\title{
COMPOSITION AND TEMPERATURE DEPENDENCE OF GIANT MAGNETORESISTANCE IN MELT-SPUN $\mathrm{Co}_{x} \mathrm{Cu}_{100-x}$ RIBBONS
}

\author{
B. IdzIKowsKi* ${ }^{*}$ K. Nenkov ${ }^{\dagger}$, A. Handstein, A. HÜtTen \\ AND K.-IH. MÜLLER
}

Institute for Solid State and Materials Research Dresden

P.O. 270016, 01171 Dresden, Germany

\begin{abstract}
Structure, magnetic properties and magnetoresistance in as-quenched and annealed $\mathrm{Co}_{x} \mathrm{Cu}_{100-x}$ samples were investigated. Homogeneous metastable $\mathrm{Co}_{x} \mathrm{Cu}_{100-x}$ alloys were prepared by the single-roller technique. The maximum value of magnetoresistance is shifted to higher annealing temperatures with increasing measuring temperature. At higher measuring temperatures the magnetoresistance is not saturated in fields as high as $16 \mathrm{~T}$. Susceptibility measurements showed the formation of hcp-structured Co clusters. For small cobalt concentrations there is a transition from giant magnetoresistance to the normal anisotropic magnetoresistance.
\end{abstract}

PACS numbers: 75.70.Pa, 72.15.Eb, 81.40.Rs

Giant changes in magnetoresistivity were found at first in thin films containing ferromagnetic granules embedded in a non-magnetic matrix [1,2]. Later it was found that some bulk heterogeneous systems prepared by rapid quenching or mechanical alloying also show this effect $[3,4]$. Many of these granular alloys may have values of the giant magnetoresistance (GMR) effect $M R(H)=[R(H)-R(0)] / R(0)$ as high as or even larger than their counterparts prepared as multilayers or thin films. In this case the effect is due to the spin-dependent scattering of electrons on superparamagnetic clusters embedded in a non-magnetic well conducting matrix. The influence of Co in melt-spun $\mathrm{Co}_{x} \mathrm{Cu}_{100-x}$ ribbons is described in this paper.

High-purity elements ( $\mathrm{Cu} 99.9$, Co 99.998) were used to melt the starting ingots in an arc-furnace. From these $\mathrm{Co}_{x} \mathrm{Cu}_{100-x}$ master alloys with $x=0,0.5,1$, $5,8,10,12,15,20$ and 25 metastable ribbons were prepared using the single-roller technique. The liquid alloy was jetted through a quartz nozzle on a $\mathrm{Cu}$ wheel (diameter $20 \mathrm{~cm}$ ) at surface velocities from 30 to $40 \mathrm{~m} / \mathrm{s}$ in an Ar filled chamber.

* On leave from the Institute of Molecular Physics, Polish Academy of Sciences, Poznan, Poland.

IOn lea ve from the Int. Laboratory of High Magnetic Fields and Low Temperatures, Wrocław, Poland. 
The samples were annealed from temperatures $t_{\mathrm{a}}=400^{\circ} \mathrm{C}$ to $600^{\circ} \mathrm{C}$ for $30 \mathrm{~min}$ to obtain various states of microstructurc. The electrical resistivity was measured with the de four-point method in the temperature range from $5 \mathrm{~K}$ to $300 \mathrm{~K}$ at magnetic fields up to $16 \mathrm{~T}$. The ac susceptibility of zero-field cooled samples was measured in a Lake Shore susceptometer.

Figure 1a shows the cobalt concentration dependence of GMR of samples after annealing at $420^{\circ} \mathrm{C}$ measured at $10 \mathrm{~K}$. The greatest GMR values were found for alloys with $x=10$ and $12 . \mathrm{Co}_{10} \mathrm{Cu}_{90}$ was chosen for the detailed investigation. For a comparison $\mathrm{Cu}$ ribbons have also been investigated (i.e. $x=0$ ) which exhibit a normal MR of about $17 \%$ at $\mu_{0} H=5 \mathrm{~T}$ (see inset of Fig. 1a). Figure $1 \mathrm{~b}$ shows that the conditions for optimal GMR values strongly depend on the temperatures of annealing and measurement. E.g. for $x=10$ the maximum GMR (5 T) values are $34 \%$ and $11 \%$ for $T=10 \mathrm{~K}$ and $293 \mathrm{~K}$, where the respective annealing temperatures differ by about $75 \mathrm{~K}$.

Figure 2a shows the well-known field dependence of GMR for $\mathrm{Co}_{10} \mathrm{Cu}_{90}$ samples. Very small differences between the GMR values measured at $10 \mathrm{~K}$ with the applied field perpendicular and parallel to the current directions are typical for granular solids. The temperature dependence of the susceptibility $\chi$ shows the typical behaviour of superparamagnetic particles with blocking temperatures $T_{\mathrm{B}} \approx$ $18 \mathrm{~K}$ in the case of annealing from $420^{\circ} \mathrm{C}$ to $500^{\circ} \mathrm{C}$ as shown for $x=10 \mathrm{in} \mathrm{Fig.} 2 \mathrm{~b}$. But for higher $t_{\mathrm{a}}$ the peaks were broadened and shifted to higher temperature regions. This is probably due to the change from fcc- to hcp-structure type because of the growth of Co clusters. An increase in the anisotropy constant $K_{1}$ due to this structural change [5] causes the shift of $T_{\mathrm{B}}$ according to the proportionality of $T_{\mathrm{B}}$ to the anisotropy energy [6]. The absolute value of $\chi$ grows and after structural
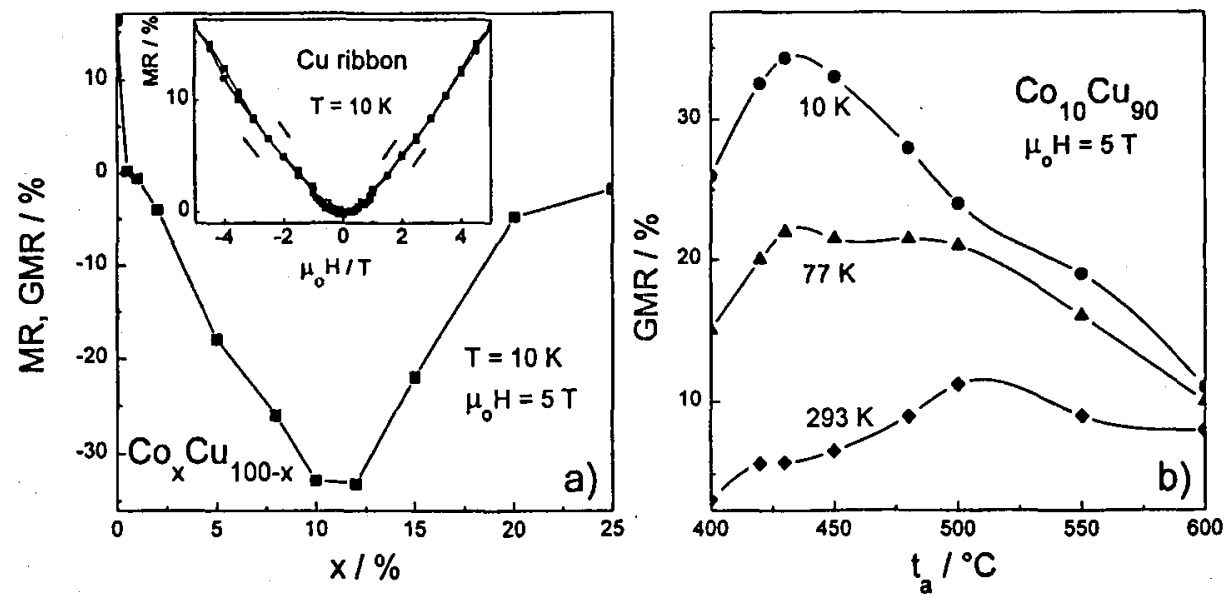

Fig. 1. Giant magnetoresistance of $\mathrm{Co}_{x} \mathrm{Cu}_{100-x}$ samples (a) in dependence on the Co content afier annealing at $420^{\circ} \mathrm{C}$ (inset: $\mathrm{MR}$ vs. field for $\mathrm{Cu}$ ribbon) and (b) for $x=10$ in dependence on the annealing temperature measured at $T=10,77$ and $293 \mathrm{~K}$, and $\mu_{0} H=5 \mathrm{~T}$. 

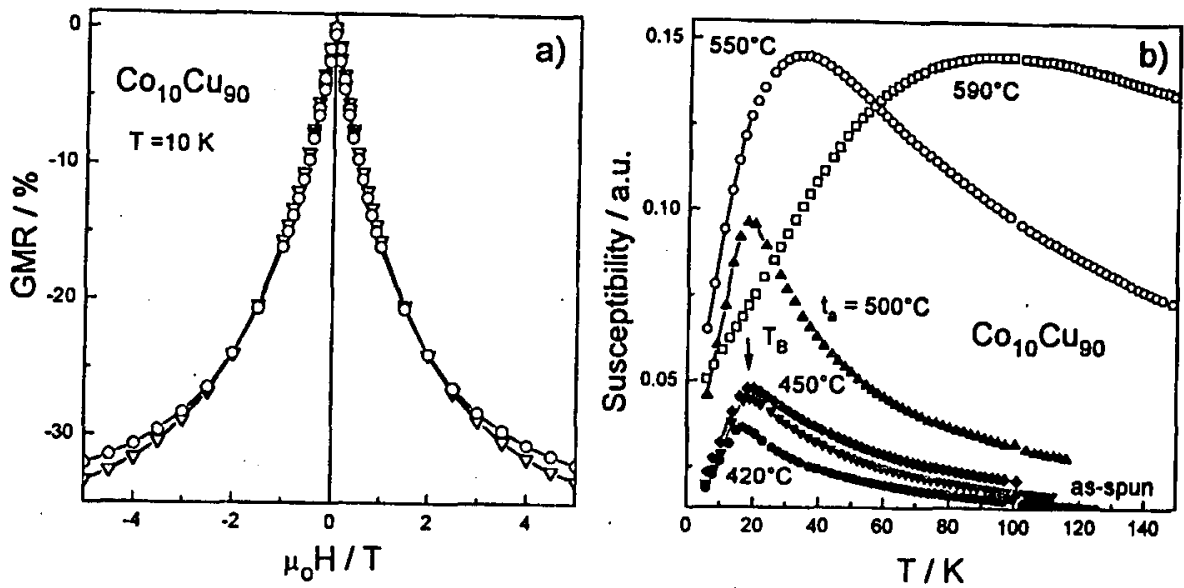

Fig. 2. $\mathrm{Co}_{10} \mathrm{Cu}_{90}$ : (a) giant magnetoresistance vs. external field of samples annealed at $420^{\circ} \mathrm{C}$ and measured at $10 \mathrm{~K}$ with the applied field perpendicular $(\nabla)$ and parallel (o) to the current direction and (b) temperature dependence of the ac susceptibility for samples annealed at different temperatures.
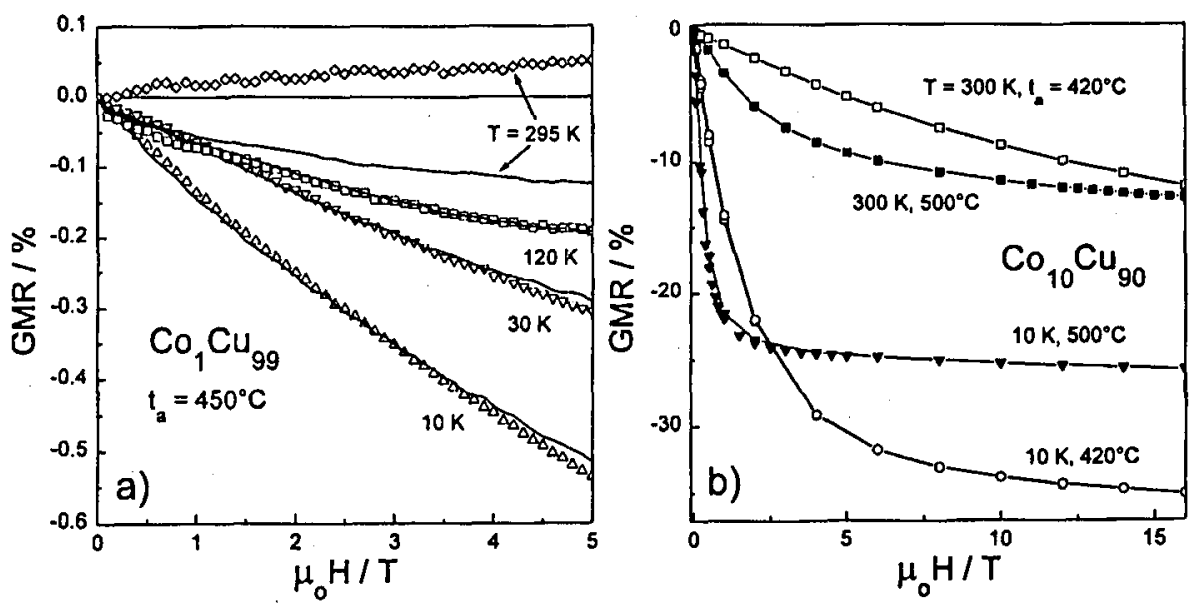

Fig. 3. Field dependence of the magnetoresistance for $\mathrm{Co}_{x} \mathrm{Cu}_{100-x}$ samples with (a) $x=1$ measured perpendicular (solid lines) and parallel (symbols) to applied field and with (b) $x=10$ annealed and measured at different temperatures.

clianging of Co grains this value decreases. It could be explained by taking into account a possible solution of $\mathrm{Co}$ in the $\mathrm{Cu}$ matrix after annealing at $t_{\mathrm{a}}$ between $500^{\circ} \mathrm{C}$ and $600^{\circ} \mathrm{C}$. The mean particle size could be roughly estimated [6] using the formula $30 k_{\mathrm{B}} T_{\mathrm{B}}=K_{1}\langle V\rangle$, where $k_{\mathrm{B}}$ is the Boltzmann constant and $\langle V\rangle$ is the mean volume of superparamagnetic particles. If both or only one of the values of $K_{1}$ or $\langle V\rangle$ increase, the blocking temperature also increases. The roughness of 
a $\langle V\rangle$ estimation is mainly due to the complicated origin of magnetic anisotropy in very small particles [6]. The effective anisotropy constant for such particles is usually larger than for bulk material. $K_{1}=-3 \times 10^{5} \mathrm{~J} \mathrm{~m}^{-3}$ and $T_{\mathrm{B}}=18 \mathrm{~K}$ give the value of cluster diameter of about $3.6 \mathrm{~nm}$.

As shown in Fig. 3a there is a transition from GMR to the normal anisotropic magnetoresistance (AMR) for small cobalt concentrations. Thus a $\mathrm{Co}_{1} \mathrm{Cu}_{99}$ sample heat treated at $450^{\circ}$ for 30 min shows an isotropic GMR effect from $10 \mathrm{~K}$ to $120 \mathrm{~K}$ but the behaviour is AMR dominated at $300 \mathrm{~K}$. A similar behaviour was also found for samples with $x=0.5$.

As seen in Fig. 3b the MR of $\mathrm{Co}_{10} \mathrm{Cu}_{90}$ is not saturated at higher temperatures in fields as high as $16 \mathrm{~T}$. The GMR effect. of samples annealed at $420^{\circ} \mathrm{C}$ and $500^{\circ} \mathrm{C}$ and measured at $300 \mathrm{~K}$ practically reaches the same value of $13 \%$ at $16 \mathrm{~T}$. The high-change rates of MR were obtained for samples with a nearly linear high field behaviour, e.g. up to $0.7 \% / \mathrm{T}$ for a $\mathrm{Co}_{15} \mathrm{Cu}_{85}$ sample. The difference in the field dependence may be caused by the variety of Co clusters formed after various heat treatments as discussed above, i.e. the fcc- and hcp-structured clusters show different behaviour at $300 \mathrm{~K}$.

\section{References}

[1] A.E. Berkowitz, J.R. Mitchell, M.J. Carcy, A.P. Young, S. Zhang, F.E. Spada, F.T. Parker, A. IIütten, G. Thomas, Phys. Rev. Lett. 68, 3745 (1992).

[2] J.Q. Xiao, J.S. Jiang, C.L. Chien, Phys. Rev. Lelt. 68, 3749 (1992).

[3] J. Wecker, R. von IIelmolt, L. Schultz, K. Samwer, Appl. Phys. Lett. 62, 1985 (1993).

[4] K. Ounadjela, A. Herr, R. Poinsot, J.M.D. Coey, A. Fagan, C.R. Staddon, D. Daniel, J.F. Gregg, S.M. Thompson, K. O'Grady, S. Grieves, J. Appl. Phys. 75, 6921 (1994).

[5] X. Liu, M.M. Steiner, R. Sooryakumar, G.A. Prinz, R.F.C. Farrow, G. Harp, Phys. Rev. B 53, 12166 (1996).

[6] I.S. Jacobs, C.P. Bean, in: Magnetism, Eds. G.T. Rado, H. Suhl, Vol. III, A ademie Press, New York 1963, p. 271. 